\title{
Myristic Acid Derived Sophorolipid: Efficient Synthesis and Enhanced Antibacterial Activity
}

\author{
Isha Abhyankar, Ganesh Sevi, Asmita A. Prabhune,* Anuya Nisal,* and Santhakumari Bayatigeri \\ Cite This: ACS Omega 2021, 6, 1273-1279 \\ Read Online
}

ABSTRACT: Microbial glycolipids are one of the most interesting alternatives to chemical-based surfactants as they exhibit improved biodegradability and less toxicity. However, their potential has been limited because of specificity of the yeast toward fatty acids having a carbon 16 or carbon 18 chain. This study focuses on sophorolipid (SL) production by the yeast Starmerella bombicola using myristic acid, a medium-chain carbon-14 fatty acid that has not been used as a substrate for SL production. The production was optimized for inoculum size and lipophilic substrate concentration. Furthermore, we also studied the effect of medium-chain fatty acid on yeast cell growth and optimized the process for excellent yield. The myristic acid SL (MASL) so synthesized consisted of mono- and diacetylated forms with preferential glycosylation at the methyl end group, as determined by high-resolution mass spectrometry. Individual congeners of the crude mixture were separated using dry column chromatography and then structurally characterized by mass spectrometry. The synthesized MASL was also shown to have promising surface tension, lowering abilities with a low CMC of $14 \mathrm{mg} / \mathrm{L}$.

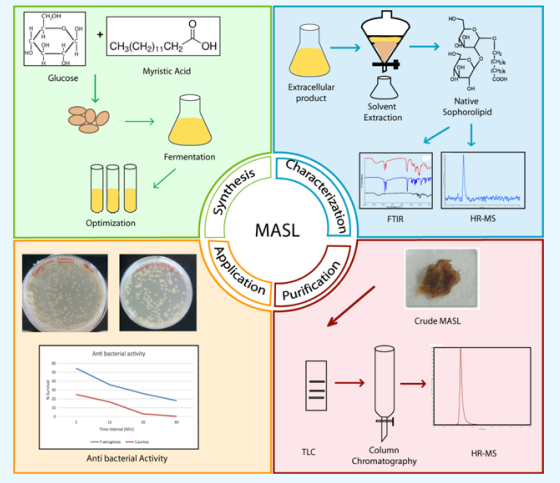
The SL derived from myristic acid exhibited superior antibacterial activity as compared to SL derived from oleic acid. MASL was also found to be more potent against Gram-positive organisms as compared to Gram-negative organisms. This work, therefore, demonstrates successful synthesis of myristic acid-derived SL and its superior antibacterial activity, establishing a promising future for this biosurfactant.

\section{INTRODUCTION}

Sophorolipids (SLs) have emerged as promising substitutes for petroleum-derived conventional surfactants as they are biodegradable, non-toxic, and cost-effective. ${ }^{1,2}$ These molecules have good surface tension-lowering abilities and varied biological properties such as antibacterial, ${ }^{3}$ antifungal, ${ }^{4}$ antiviral, $^{5}$ and anticancer properties. ${ }^{6}$

SLs are biosynthesized using a carbohydrate (sophorose) as the hydrophilic head and fatty acid as the hydrophobic tail. Varying the fatty acid substrate enables tailormade biosynthesis of different SLs. The preferred range of chain length of fatty acid for SL synthesis is C16-18. This limitation is attributed to (i) the substrate specificity of the enzymes cytochrome P450 monooxygenases (CYP52M1) and uridine diphosphate glucosyltransferase (UGTA1) and (ii) high preponderance of $\mathrm{C} 18$ in the de novo product. Therefore, SLs are commonly synthesized using fatty acids with 16-18 carbon atom chains. These fatty acid include stearic acid, oleic acid, linoleic, linolenic, and palmitic or a mixture of oils (vegetable/residual oils). ${ }^{7-10}$ Nevertheless, SLs derived from shorter chain lengths will have better physical characteristics such as improved water solubility and better CMC values. ${ }^{11}$

The influence of fatty acid chain length on SL biosynthesis and product formation is only partially understood. Van Bogeart $^{12,13}$ reported the ill effects of shorter chain fatty acid (C8-10) on the yeast cell growth and yield of SL. However, short- and medium-chain length SLs have been successfully produced using different substrates such as secondary alcohol (C12-C14), coconut oil, and hydroxy fatty acids ${ }^{11,14,15}$ via chemical, biological, and biocatalytic methods. The use of pure medium/short-chain fatty acid as a sole lipophilic source for synthesizing SL is yet to be explored. As the structure of the synthesized SL substantially depends on the producing organism and the fermentation condition, ${ }^{13}$ appropriate process optimization is necessary. Synthesis of such SLs would require circumventing the fermentation process. ${ }^{7}$

The synthesized SL is generally a mixture of molecules varying in the degree of acetylation, internal esterification between the carboxylic group of fatty acid and 4 " position of the sophorose molecule, hydroxylation of fatty acid, and chain length of fatty acid. Acidic SLs are water-soluble and aid in surfactant ability and solubility, whereas lactonic ones impart biological properties. For a deeper understanding of functional

Received: September 23, 2020

Accepted: December 17, 2020

Published: January 4, 2021 
diversity, purification of the congeners is extremely essential. $^{16,17}$

Our study describes the fundamental variables that influence the production of short-chain SLs. First, we demonstrate the green synthesis of SL using a novel substrate myristic acid [MASL]. Second, the media composition, culture conditions, and the relationship between fatty acid chain length and SL structural diversity were investigated. Furthermore, the synthesized MASL was purified and characterized using FTIR, CMC, and HR-MS. Finally, we demonstrate that MASL is an extremely potent antibacterial agent against both Gram-positive and Gram-negative bacteria.

\section{RESULTS AND DISCUSSION}

Fatty acids of length $\mathrm{C} 16-\mathrm{C} 18$ such as oleic acid are most preferred substrates of enzymes involved in SL biosynthesis by Starmerella bombicola. Therefore, the first objective of this study was to optimize the synthesis of myristic acid SL (C14) with respect to yeast cell growth and yields. Preliminary optimization studies were performed using different media compositions (resting cell, growth-associated, induction, and nitrogen depletion). The results revealed that the maximum yield $(12 \mathrm{~g} / \mathrm{L})$ of MASL was obtained with the resting cell method (Figure 1). In the resting cell method, the cells are

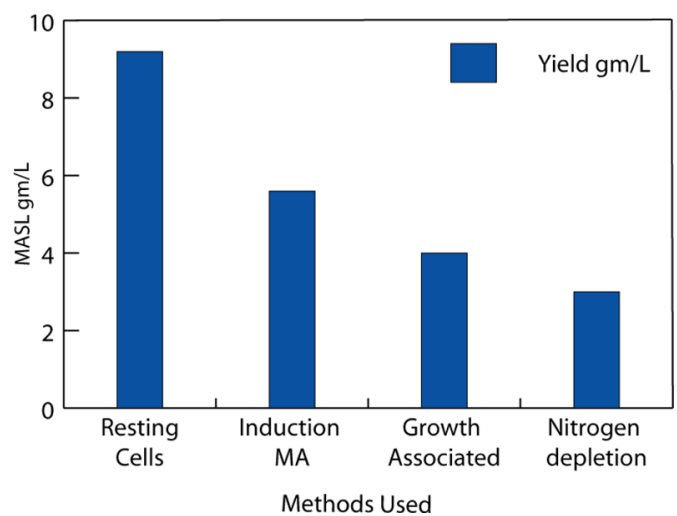

Figure 1. Effect of different fermentation methods (resting cells, induction using myristic acid, growth-associated, and nitrogen depletion) on MASL yield obtained after 7 days of fermentation at $28^{\circ} \mathrm{C}$.

harvested after the growth phase and subjected to new media during fermentation. Thus, the cells have fresh supply of components for production of SLs. Also, introduction of myristic acid during the growth phase leads to acclimatization of the cells to the unconventional substrate, resulting in good yield. It can thus be concluded that the resting cell method along with induction works best for synthesis of the shortchain derived SL-MASL (refer Figure 1). The use of myristic acid as the substrates also has few advantages: its usage is FDAapproved and is also declared GRAS clear by FEMA. ${ }^{18,19}$

Our studies also showed that the optimized method of MASL production had no adverse effect on the cell mass (refer Figure 2). The probable reason for successful synthesis of this SL is its role in myristoylation: a lipid modification involving the addition of myristic acid to the $\mathrm{N}$ terminal of glycine. This lipidation reaction plays an essential role in protein-protein interaction and signal transduction pathways. Therefore, exogenous supply of myristic acid through the fermentation media activates the $N$-myristoyl transferase enzymes, which are

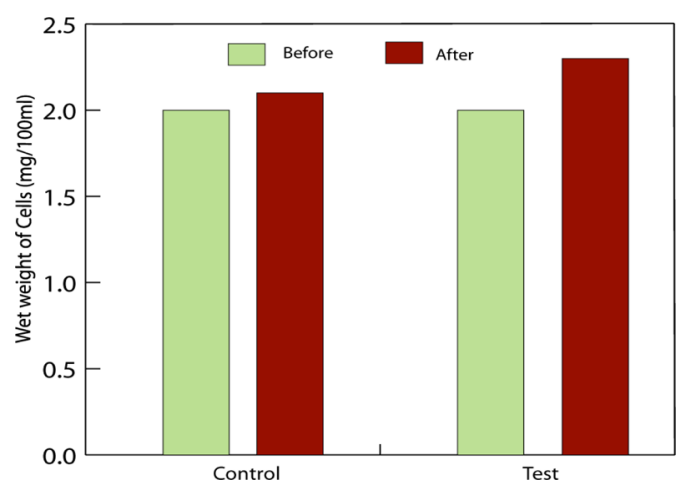

Figure 2. Effect of the lipophilic substrate (myristic acid) on growth of yeast cells. Control: fermentation performed without the lipophilic substrate and test: incorporation of myristic acid as the lipophilic substrate.

involved in myristoylation. Moreover, myristic acid acts as a hydrophobic anchor in the lipid bilayer of the cell, thereby facilitating the association of $G$ protein with the plasma membrane. Therefore, myristic acid is not considered foreign by the cell and is easily incorporated into the enzymatic machinery, further leading to SL synthesis. ${ }^{20,21}$

S. bombicola possesses the inherent ability to synthesize the SL for its metabolism, and as a defense mechanism, this is known as the de novo product. This is carried out by the fatty acid synthase system (FAS) of the cell. Nguyen studied the correlation between the FAS system and fatty acid profile of the cell using a wide range of fatty acids (C14-C20) and concluded that the exogenous supply of myristic acid is indeed beneficial for the growth of the yeast cells. ${ }^{22}$ These studies agree with our results from the optimization studies and thereby verify that myristic acid, as the sole lipophilic substrate, is not harmful to the yeast cells.

Characterization of the SL. The preliminary characterization of MASL (TLC, oil displacement) is included in the Supporting Information. (refer Figures S1 and S2). The spectroscopic characterization of SLs is included below.

FTIR Spectroscopy. Figure 3 shows the FTIR spectra of myristic acid, glucose, and the crude-synthesized SL. Myristic acid showed peaks at $\sim 1400-1500,2918$, and $2854 \mathrm{~cm}^{-1}$, which correspond to the $-\mathrm{CH}_{2}$ vibrations. The peak at 1687



Figure 3. FTIR spectra of crude MASL. 
Table 1. Different Structural Modifications of MASL Based on Acetylation

\begin{tabular}{|c|c|c|c|c|c|c|c|}
\hline \multirow{2}{*}{ Components } & \multirow{2}{*}{ Structures } & \multirow{2}{*}{$\begin{array}{r}\text { Formula } \\
\text { (Acidic) }\end{array}$} & \multicolumn{2}{|c|}{ Mass } & \multirow[b]{2}{*}{$\begin{array}{l}\text { Formula } \\
\text { (Lactonic) }\end{array}$} & \multicolumn{2}{|c|}{ Mass } \\
\hline & & & \begin{tabular}{|c|}
$\begin{array}{c}\text { Protonated } \\
\text { Molecular } \\
\text { ion }\end{array}$ \\
\end{tabular} & $\begin{array}{l}\mathrm{Na} \\
\text { Adduct }\end{array}$ & & \begin{tabular}{|c|}
$\begin{array}{c}\text { Protonated } \\
\text { Molecular } \\
\text { ion }\end{array}$ \\
\end{tabular} & $\begin{array}{c}\mathrm{Na} \\
\text { Adduct }\end{array}$ \\
\hline $\begin{array}{c}\mathrm{No} \\
\text { acetylation } \\
\mathrm{CH}_{3}\end{array}$ & (1) & $\mathrm{C}_{26} \mathrm{H}_{48} \mathrm{O}_{13}$ & 569.31 & 591.22 & $\mathrm{C}_{26} \mathrm{H}_{46} \mathrm{O}_{12}$ & 551.63 & 573.28 \\
\hline $\begin{array}{c}\text { Mono } \\
\text { acetylation } \\
\mathrm{CH}_{3}\end{array}$ & & $\mathrm{C}_{28} \mathrm{H}_{50} 0_{14}$ & 611.3 & 633.69 & $\mathrm{C}_{28} \mathrm{H}_{48} \mathrm{O}_{13}$ & 593.31 & 615.29 \\
\hline $\begin{array}{c}\mathrm{Di} \\
\text { acetylation } \\
\mathrm{CH}_{3}\end{array}$ & 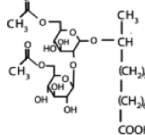 & $\mathrm{C}_{30} \mathrm{H}_{52} \mathrm{O}_{15}$ & 653.72 & 675.72 & $\mathrm{C}_{30} \mathrm{H}_{50} \mathrm{O}_{14}$ & 635.71 & 657.31 \\
\hline
\end{tabular}

$\mathrm{cm}^{-1}$ corresponds to the carbonyl stretching. Characteristic peaks of glucose are seen at 1030 and $984 \mathrm{~cm}^{-1}$, which correspond to the $\mathrm{C}-\mathrm{O}$ stretching vibration. The broad peak in the 3200 and $3400 \mathrm{~cm}^{-1}$ corresponds to the $-\mathrm{OH}$ stretching. ${ }^{23}$ For MASL, the broad peak at $\sim 3392 \mathrm{~cm}^{-1}$ corresponds to $\mathrm{O}-\mathrm{H}$ stretching, which is present in the glucose molecule. Peaks at 2918 and $2846 \mathrm{~cm}^{-1}$ represent symmetrical and asymmetrical stretching of the $-\mathrm{CH}_{2}$ group of fatty acid, respectively. A peak at $1695 \mathrm{~cm}^{-1}$ corresponds to- $\mathrm{CH}_{2}$ bending. Stretching of $\mathrm{C}-\mathrm{O}-\mathrm{C}$ in the ether bond is represented at 1084 and $1030 \mathrm{~cm}^{-1}$. Thus, the FTIR spectra of MASL provide sufficient evidence that the synthesized compound contains both myristic acid and glucose moieties, and the ether peak is an indication of the presence of the SL molecule.

LC-HRMS. SL synthesis occurs in the cytosolic environment of the cell. Biosynthesis begins by activation of fatty acid by hydroxylation, catalyzed by the microbial enzyme cytochrome P450 monooxygenase. Hydroxylation occurs at the terminal or subterminal region of the fatty acid. The second step involves attachment of the sophorose unit to the fatty acid molecule through an ether bond by glucosyltransferase I and II. Upon glycosylation, acidic non-acetylated SLs are obtained. Acidic SL is characterized by the free fatty acid chain, whereas the lactonic form results in the formation of a closed ring structure because of internal esterification at the carboxylic end of fatty acid with $\mathrm{C} 4$ of the sophorose moiety. ${ }^{2}$

Further modifications include acetylation at the $\mathrm{C} 6$ position of the glucose moieties, resulting in the formation of monoacetylated and diacetylated SL molecules. ${ }^{23}$ HRMS analysis revealed that MASL is a mixture of acidic and lactonic molecules (Table 1) with the preferred site for glycosylation through the methyl group. Mono- and diacetylated acidic and lactonic structures were also elucidated from the analysis. Refer to Supporting Information for spectra of each modification (S4-S6)

Glycosylation at the other end (carboxylic end) is not prevalent in the case of MASL. The different structures of MASL have been summarized in Table 1. The presence of both acidic and lactonic forms of SLs is further supported by HPLC data included in the Supporting Information (Figures S3).

Purification of SLs. As described earlier, the crude SL is a mixture of acidic and lactonic types of SLs with acetylation, diacetylation, or monoacetylation. The purification of this crude SL was performed in dialysis tubing, which resulted in separation of the mixture into well-defined bands. The yield of all the bands was $80 \%$ of the initial crude SL loaded onto the column. These separated SLs were then run on TLC, and each fraction depicted a single band, thereby confirming their purity.

The individual fractions from purification were further analyzed using LC-HRMS to identify the molecular weight of individual components. The molecular weights of each congeners were similar to that obtained in the crude mixture (refer Table 1). The different modifications obtained from the congeners were: acidic SL, monoacetylated acidic SL, monoacetylated lactonic, diacetylated acidic form, and diacetylated lactonic SL. Refer to the Supporting Information for the mass spectra of each individual congener (Figures S7S11).

Surface Tension. In dilute solutions, surfactants behave as normal solute molecules, but as the concentration increases, abrupt changes in the physical properties are observed. This phenomenon is due to the formation of aggregates or micelles. The critical micellar concentration (CMC) value is measured using any micelle-influenced physical properties as a function of concentration. ${ }^{1}$ In the present work, the surface tension of MASL was measured for concentrations ranging from 0.01 to 1 $\mathrm{mM}$. As the concentration increased, the surface tension was found to continuously decrease. This reduction in surface tension is a further confirmation of successful synthesis of the SL molecule. Refer to Figure 4. After a specific concentration of $14 \mathrm{mg} / \mathrm{L}$, no significant decrease in the surface tension was observed because of the formation of micelles in the solution. Thus, it can be concluded here that MASL reduced the surface tension of water to $35-37 \mathrm{mN} / \mathrm{m}$ and has a CMC value of 14 $\mathrm{mg} / \mathrm{L}$. 




Figure 4. CMC and surface tension reduction by synthesized MASL.

The surfactant ability of molecules depends upon chain length, charge, branching, and degree of unsaturation. The micellization process is governed by the hydrophobic moiety of the surfactant. ${ }^{24}$ Bulky molecules require more time to form micelles, thereby increasing the CMC of the molecule. The reported CMC value of SLs derived from oleic acid lies in the range $130-140 \mathrm{mg} / \mathrm{L}$ and that of stearic acid-derived SLs is $37.9 \mathrm{mg} / \mathrm{L}^{25}$ A comparative study of different SLs (oleic, linolenic, and stearic acid) by Foglia et al. reports that as the chain length increases, the CMC values also increase. ${ }^{26}$ For oleic acids and linolenic acids, being unsaturated fatty acids with double and triple bonds, the CMC value is eccentrically increased. Similarly, for stearic acid, being a saturated molecule, the CMC value is low.

This is in agreement with our observations. The CMC value of MASL is distinctly low as compared to other SLs and thus makes MASL a promising candidate for various commercial surfactant applications.

Antibacterial Activity. SLs have been widely studied for their antimicrobial activities. They are increasingly being looked at as green, eco-friendly, and cost-effective alternatives to combat the global problem of antimicrobial resistance. In this regard, the antimicrobial ability of MASL against different bacteria was studied. Oleic acid-derived SL (OASL) was used as a control because much has already been reported about its antimicrobial properties. ${ }^{3}$

The antimicrobial activity of MASL was assessed against Gram-positive S. aureus and the Gram-negative bacteria $P$. aeruginosa. Staphylococcus aureus is a typical habitat of the gastrointestinal tract and skin surfaces and is capable of causing abscesses, cellulitis, food poisoning, and septic infections. $S$. aureus has intrinsically developed resistance to antibiotics, thereby resulting in resistant species such as MRSA. P. aeruginosa is an opportunistic Gram-negative pathogen, associated mainly with hospital infection. It can develop biofilms, thereby leading to chronic diseases. It is also developing resistance to antibiotics over time. ${ }^{1}$

MASL exhibited an excellent antibacterial activity against both the organisms. The \% survival of $S$. aureus dropped to $\sim 3 \%$ with a concentration of $150 \mu \mathrm{g} / \mathrm{mL}$ and with an exposure time of $30 \mathrm{~min}$ (Figure $5 \mathrm{~A}$ ). Above $350 \mu \mathrm{g} / \mathrm{mL}$ concentration, complete inhibition of the organism was observed after $15 \mathrm{~min}$. Myristic acid alone showed no activity against $S$. aureus. The MIC of MASL for S. aureus is $150 \mu \mathrm{g} / \mathrm{mL}$. In comparison, OASL did not show any inhibition at a similar concentration (Figure 5B). Representative images of plates for all other organisms have been included in the Supporting Information (Figures S12, S13).
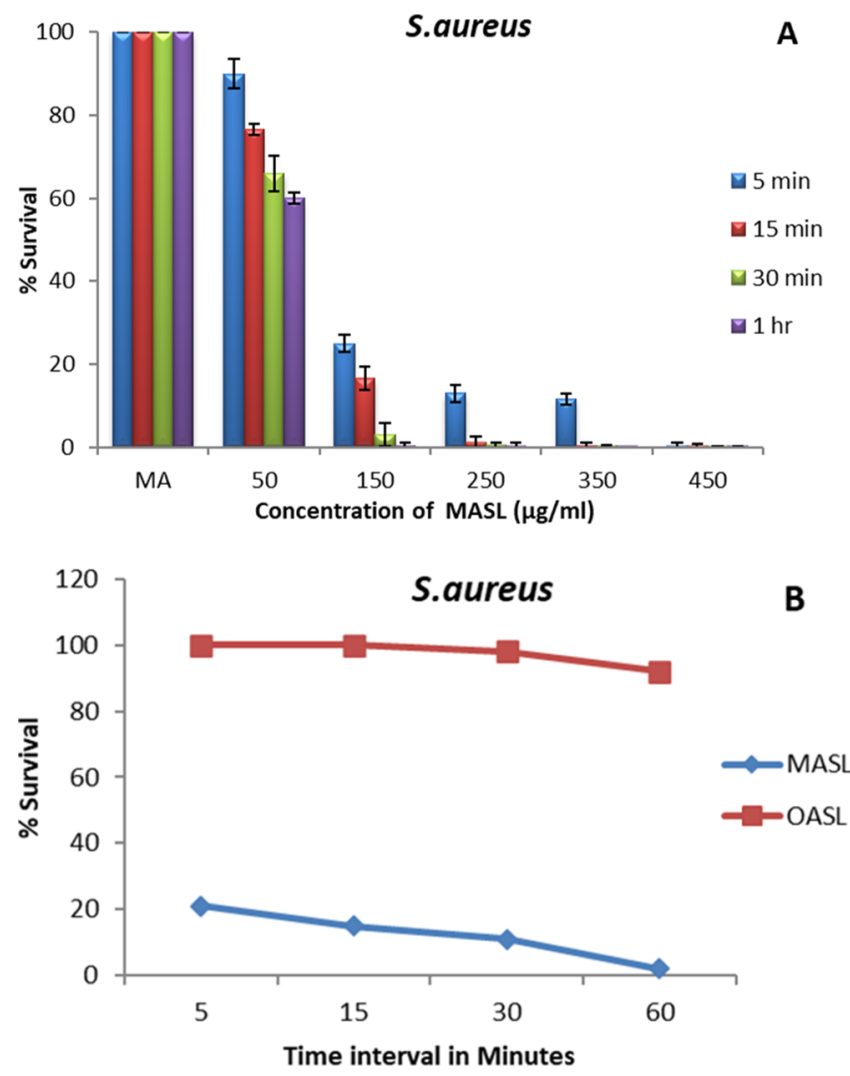

Figure 5. Antibacterial activity of MASL against S. aureus. (A) \% Survival at different concentrations $(50-450 \mu \mathrm{g} / \mathrm{mL})$ of MASL and at different time points (5-60 min). Pure myristic acid (MA) was used as the control (concentration $450 \mu \mathrm{g} / \mathrm{mL}$ ). (B) Comparison of MASL with OASL in terms of time intervals. Concentration of OASL is equal to MIC of MASL.

In the case of $P$. aeruginosa, $18 \%$ survival was observed when $350 \mu \mathrm{g} / \mathrm{mL}$ MASL was employed with an exposure time of $1 \mathrm{~h}$ (Figure 6A). For control, 3\% inhibition was observed after $1 \mathrm{~h}$ of incubation. In comparison with OASL, 30\% survival was observed after $1 \mathrm{~h}$ (Figure 6B).

From the results, it is evident that MASL is more potent toward Gram-positive organisms than Gram-negative organisms (Figures 5 and 6). This phenomenon may be due to the differences in the structural orientation of the bacterial cell wall. Gram-negative bacteria tend to be more hydrophilic as compared to Gram-positive bacteria because of the lower predominance of peptidoglycan in the cell wall. SLs, being amphiphilic, assist in reducing the hydrophobicity of the bacterial cell wall, thereby being more potent on the Grampositive bacterial membrane as compared to the Gram-negative bacterial membrane. ${ }^{27}$ Reduction in the hydrophobicity results in disruption of the membrane, thus causing leakage of the cellular contents. ${ }^{28}$

The antimicrobial properties of SLs vary depending on the chain length and degree of unsaturation of the hydrophobic group. MASL was observed to exhibit better antibacterial activity as compared to OASL. Joshi-Navare and Prabhune reported results for OASL against E. coli and $S$. aureus with concentrations of 1000 and $400 \mu \mathrm{g} / \mathrm{mL}$ with an exposure time of above $6 \mathrm{~h}$ for E. coli and $4 \mathrm{~h}$ for S. aureus. According to this research, OASL has better activity against Gram-positive organisms than Gram-negative organisms. ${ }^{29}$ From the results, it is revealed that myristic acid alone is not capable of 


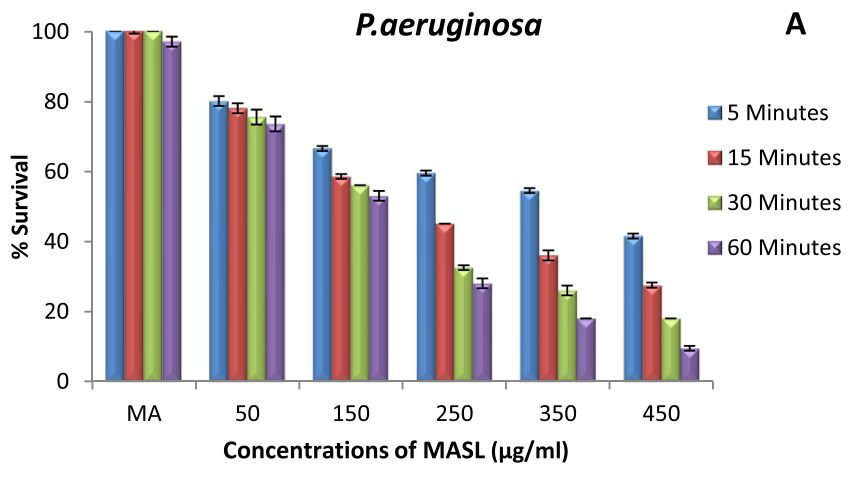

P.aeruginosa

B



Figure 6. Antibacterial activity against $P$. aeruginosa. (A) \% Survival at different concentrations $(50-450 \mu \mathrm{g} / \mathrm{mL})$ of MASL and at different time points $(5-60 \mathrm{~min})$. Only myristic acid (MA) was used as the control (concentration $450 \mu \mathrm{g} / \mathrm{mL}$ ). (B) comparison of MASL with OASL in terms of time intervals. Concentration of OASL is equal to MIC of MASL.

inhibiting the growth of organisms even at the highest concentration, whereas the SL produced from it is highly potent against both the bacteria. These results clearly show that MASL has a strong promise of being used as an antibacterial agent in the future as its amphiphilic natures distort the cell membrane, thereby inhibiting bacterial growth.

\section{CONCLUSIONS}

The toxicity of fatty acids with a short carbon chain combined with the $\mathrm{C} 16-\mathrm{C} 18$ chain length specificity of the yeast enzymes limits the avenues for producing SLs. ${ }^{30}$ In this work, we have demonstrated, using the resting cell method, the synthesis of a shorter (C14) chain SL derived from a novel source: myristic acid. This obtained myristic acid SL has been characterized structurally using spectroscopic techniques. The characterization suggests that glycosylation occurs preferentially at the methyl end group of the fatty acid chain and leads to the formation of a mixture of acidic and lactonic SL molecules, containing monoacetylated and diacetylated forms. Purification of crude MASL was carried out using column chromatography, and the individual congeners were separated and characterized. The MASL molecule also exhibited great surface tension lowering ability. The CMC value of MASL is significantly low as compared to other reported SLs. The antibacterial activity revealed that MASL is better in inhibiting Gram-positive bacteria as compared to Gram-negative bacteria, and the bactericidal activity of MASL is superior to oleic acidderived SLs. The chain length of fatty acids thus aids in improving the CMC and also the biological properties of the SL, thereby expanding the avenues for application of biosurfactants.

\section{MATERIALS}

Media components such as glucose, malt extract, peptone, and yeast extract were procured from Himedia, India. The minor components of the media, namely, $\mathrm{MgSO}_{4} \cdot 7 \mathrm{H}_{2} \mathrm{O},\left(\mathrm{NH}_{4}\right)_{2} \mathrm{SO}_{4}$, $\mathrm{Na}_{2} \mathrm{HPO}_{4}$, and $\mathrm{NaH}_{2} \mathrm{PO}_{4}$, were obtained from Qualigens, India. Myristic acid was procured from Sigma-Aldrich. All chemicals used were of analytical grade and stored according to the supplier's recommendations until further use.

\section{METHODS}

This section is divided into four parts, namely, synthesis, characterization, purification, and application.

Synthesis of SL. Microorganisms and Maintenance. S. bombicola (ATCC 22214) was used for the production of SL and was maintained on agar slants containing malt extract $(0.3$ $\mathrm{g} \%)$, glucose $(2 \mathrm{~g} \%)$, yeast extract $(0.3 \mathrm{~g} \%)$, and peptone $(0.5 \mathrm{~g} \%)$ (MGYP media) and incubated at $28{ }^{\circ} \mathrm{C}$ for $48 \mathrm{~h}$ with subculturing every 4 weeks.

The test organisms S. aureus (ATCC 9144) and Pseudomonas aeruginosa (ATCC 9027) were obtained from the National Collection of Industrial Microorganisms (NCIM), CSIR-NCL, Pune, and maintained on nutrient agar slants.

MASL was synthesized using the resting cell method. Briefly, S. bombicola was grown in $10 \mathrm{~mL}$ of MGYP broth for $24 \mathrm{~h}$ incubation $\left(28^{\circ} \mathrm{C}\right.$ and $\left.180 \mathrm{rpm}\right)$; it was transferred to $90 \mathrm{~mL}$ of growth medium (GM) [in (g/L) glucose-20, yeast extract-1, $\mathrm{MgSO}_{4} \cdot 7 \mathrm{H}_{2} \mathrm{O}-0.3, \mathrm{Na}_{2} \mathrm{HPO}_{4}-2, \mathrm{NaH}_{2} \mathrm{PO}_{4^{-}}-7$, and $\left(\mathrm{NH}_{4}\right)_{2} \mathrm{SO}_{4^{-}}$ 1 at $28{ }^{\circ} \mathrm{C}$ ] with mild shaking conditions of $180 \mathrm{rpm}$. After 48 $\mathrm{h}$ of growth, cells were harvested by centrifugation at $5000 \mathrm{rpm}$ for $20 \mathrm{~min}$. The pellet was then redispersed in the production medium $(\mathrm{PM})\left[\mathrm{in}(\mathrm{g} / \mathrm{L})\right.$; glucose- 100 , yeast extract- $1, \mathrm{MgSO}_{4}$. $7 \mathrm{H}_{2} \mathrm{O}-0.3, \mathrm{Na}_{2} \mathrm{HPO}_{4}-2, \mathrm{NaH}_{2} \mathrm{PO}_{4}-7$, and $\left.\left(\mathrm{NH}_{4}\right)_{2} \mathrm{SO}_{4}-1\right]$ supplemented with $1 \%(\mathrm{v} / \mathrm{v})$ myristic acid and incubated at $28{ }^{\circ} \mathrm{C}$ at $180 \mathrm{rpm}$ shaking for 8 days. ${ }^{1,31}$

Media Optimization. Optimization studies were performed in triplicates. Different media compositions (growthassociated, resting cell, induction, and nitrogen depletion) were used for media optimization. The bioprocess of SL consists of two phases: the growth phase and production phase. In the resting cell method, the cells were grown in MGYP media along with the lipophilic substrate $(0.1 \%)$ and later transferred to production media (PM). For the induction experiment, myristic acid $(0.1 \%)$ was added to the media during the growth phase, and then, fermentation was continued in the same media (with top-up of glucose and the lipophilic substrate). For growth-associated, the MGYP media was used for both the growth and production phases (with top-up of glucose and the lipophilic substrate). Nitrogen depletion was achieved by eliminating the nitrogenous sources from the media.

Another experiment was designed to analyze the effect of shorter chain fatty acids on yeast cell growth. For this, the test sample contained myristic acid (1\%) as a lipophilic substrate for fermentation, while the control was devoid of any external lipophilic substrate, de novo fermentation. Biomass was calculated at the end of fermentation and compared.

SL Extraction. A simple one-step process was designed to obtain crude MASL. Briefly, the fermentation broth was centrifuged at $5000 \mathrm{~g}$ at $10^{\circ} \mathrm{C}$ for $20 \mathrm{~min}$. The suspended cell pellet was stored for the next cycle of fermentation. The supernatant was collected and subjected to solvent extraction using an equal volume of ethyl acetate. The obtained MASL 
was dried over $\mathrm{Na}_{2} \mathrm{SO}_{4}$ and then washed twice with $n$-hexane to eliminate the remaining hydrophobic moieties. Partially purified MASL was obtained after the evaporation of hexane under vacuum. ${ }^{1}$

Characterization of SL. Fourier Transform Infrared Spectroscopy. The chemical composition of the synthesized MASL was analyzed using Fourier transform infrared spectroscopy (FTIR). All measurements were obtained in the ATR mode on a Bruker TENSOR II instrument, and 32 runs scans in the $400-4000 \mathrm{~cm}^{-1}$ wavenumber were recorded. Myristic acid and glucose were used as the control.

High-Resolution Mass Spectrometry. The SL structure was determined by high-resolution mass spectrometry on QExactive (Thermo Scientific hybrid quadrapole-Orbitrap mass spectrometer). The $\mathrm{C} 18$ column with dimensions $3 \times 100 \mathrm{~mm}$ was used. Sample preparation was carried out in methanol. A 70:30 ACN-water solvent system was used with a flow rate of $500 \mu \mathrm{L} / \mathrm{min}$. The mass spectrometer was operated in the positive electrospray ionization mode in the full scan mode with a maximum resolution of 70,000 at $200 \mathrm{~m} / z$ and mass range 100 to $1500 \mathrm{~m} / z$. The instrumental operation conditions were as follows: spray voltage at $4.0 \mathrm{kV}$, capillary temperature at $320{ }^{\circ} \mathrm{C}$, S-lens RF level at 50 (arbitrary units), automatic gain control (AGC) at $1 \times 10^{6}$, and maximum injection time at $120 \mathrm{~ms}$. Sheath gas (nitrogen), auxiliary gas, and sweep gas were set at 35, 8, and 2 (arbitrary units), respectively. The peaks with the highest relative abundance values were correlated with $[\mathrm{M}]^{+} /\left[\mathrm{M}+\mathrm{NH}_{4}\right]^{+} /[\mathrm{M}+\mathrm{Na}]^{+}$, that is, the native protonated molecular ion and sodium adduct. Thus, based on the $m / z$ ratio (mass to charge ratio), the structures were putatively identified.

Purification of MASL. Purification of synthesized MASL was carried out using dry column chromatography. Silica gel (UV-visible GF $254 \mathrm{~nm}$ ) with a mesh size of 100-200 was used as the packing material, and dialysis tubing was used as a dry column. Before packing the column, silica gel was activated by heating at $110{ }^{\circ} \mathrm{C}$ for $4 \mathrm{~h}$. Precisely, $100 \mathrm{~g}$ of activated silica gel was mixed thoroughly with $10 \mathrm{~mL}$ of distilled water. Distilled water was added to maintain the moisture level and for the reproducibility of the $R_{\mathrm{f}}$ value. Dialysis tubing of measurement $4 \times 40 \mathrm{~cm}$ was sealed at one end. Crude MASL (2 g) dissolved in ethyl acetate was mixed with an equal amount of dry activated silica gel, and then, the resultant slurry was packed into the column. The solvent system $(100 \mathrm{~mL})$ consisting of chloroform/methanol/water (65:15:2, v/v/v) was loaded onto the column and allowed to migrate for $2 \mathrm{~h}$ until it reached the end of the column. The column was examined under UV-visible illumination at $254 \mathrm{~nm}$. Five distinct bands with respective $R_{\mathrm{f}}$ were observed which were cut out with a surgical knife. The individual gel slices were added to ethyl acetate and stirred to form a slurry. The resulting supernatant was collected and rotary-evaporated. Each fraction was further analyzed by HR-MS. ${ }^{32}$

Surface Tension. Surface tension was measured using a Kruss K-11 tensiometer, using a Wilhelmy plate method. To calibrate the instrument, first, the surface tension of water was measured $(71 \mathrm{mN} / \mathrm{m})$ at room temperature $\left(25^{\circ} \mathrm{C}\right)$. Surface tension was measured for different concentrations of SLs. The graph of surface tension against concentration was plotted. The critical micellar concentration was obtained as the point of inflection between the fitted trend lines for the high concentration regime and low concentration regime.
Antibacterial Activity. The antibacterial activity was assayed using the contact method as per the protocol described earlier. ${ }^{1}$ Briefly, the test organisms $S$. aureus and P. aeruginosa were grown in Luria Bertani broth and incubated for $24 \mathrm{~h}$ at 28 and $37{ }^{\circ} \mathrm{C}$, respectively. The cell pellet was harvested by centrifugation at $5000 \mathrm{rpm}$ for $15 \mathrm{~min}$ and washed with saline. The supernatant was discarded, and the pellet was resuspended in saline and recentrifuged at $5000 \mathrm{rpm}$ for $15 \mathrm{~min}$. Serial dilutions were prepared up to $10^{-5}$. The cell count was quantified by adjusting the OD to 0.1 at $600 \mathrm{~nm}$. MASL was diluted to $50,150,250,350$, and $450 \mu \mathrm{g} / \mathrm{mL}$ concentration for all organisms. Bacterial culture was mixed with each dilution of MASL and incubated up to $1 \mathrm{~h}$. Aliquots of $0.1 \mathrm{~mL}$ were withdrawn at intervals of $15 \mathrm{~min}$ and plated on LB agar. Two controls were used: only bacterial cells and only lipophilic substrate. In addition, OASL was used as a positive control. ${ }^{4}$ For each experiment, myristic acid $(450 \mu \mathrm{g} / \mathrm{mL})$ was used as a control. The plates were then incubated at $37^{\circ} \mathrm{C} / 28{ }^{\circ} \mathrm{C}$ for 24 h. All experiments were performed in triplicates. ${ }^{1}$ After incubation, the number of colonies was counted, and \% survival was calculated using the formula

$\%$ cell survival $=100 \times\left(N_{\mathrm{T}} / N_{\mathrm{C}}\right)$

$N_{\mathrm{T}}$ : number of bacterial colonies on plates.

$N_{\mathrm{C}}$ : number of colonies observed on the control plate.

\section{ASSOCIATED CONTENT}

\section{Supporting Information}

The Supporting Information is available free of charge at https://pubs.acs.org/doi/10.1021/acsomega.0c04683.

Characterization of SLs including preliminary assays, mass spectra of modifications and congeners, antibacterial activity images, and experimental details (PDF)

\section{AUTHOR INFORMATION}

\section{Corresponding Authors}

Asmita A. Prabhune - Biochemical Sciences Division, CSIRNational Chemical Laboratory, Pune 411008, India; Academy of Scientific and Innovative Research (AcSIR), Ghaziabad 21002, India; (1) orcid.org/0000-0003-18392105; Email: asmita.prabhune@gmail.com

Anuya Nisal - PSE Division, CSIR-National Chemical Laboratory, Pune 411008, India; Academy of Scientific and Innovative Research (AcSIR), Ghaziabad 21002, India; (1) orcid.org/0000-0003-1633-7890; Phone: +91 20 25903013; Email: aa.nisal@ncl.res.in

\section{Authors}

Isha Abhyankar - PSE Division, CSIR-National Chemical Laboratory, Pune 411008, India; Academy of Scientific and Innovative Research (AcSIR), Ghaziabad 21002, India

Ganesh Sevi - CMC Division, CSIR-National Chemical Laboratory, Pune 411008, India; Academy of Scientific and Innovative Research (AcSIR), Ghaziabad 21002, India

Santhakumari Bayatigeri - CMC Division, CSIR-National Chemical Laboratory, Pune 411008, India; Academy of Scientific and Innovative Research (AcSIR), Ghaziabad 21002, India

Complete contact information is available at: https://pubs.acs.org/10.1021/acsomega.0c04683 


\section{Notes}

The authors declare no competing financial interest.

\section{ACKNOWLEDGMENTS}

The authors would like to thank Dr. Kharul and Dr. Sushama Gaikwad (CSIR-NCL) and their students for the technical support required for characterization (Surface tension and HPLC) of the compound. The authors would like to thank ICMR, New Delhi, for the fellowship. A.N. acknowledges the support of Department of Science and Technology under the SERB Extra Mural Research Grant (file no. EMRJ2017/ 001899) for financially supporting this work.

\section{REFERENCES}

(1) Dubey, P.; Selvaraj, K.; Prabhune, A. Physico-Chemical, Analytical and Antimicrobial Studies of Novel Sophorolipids Synthesized Using Cetyl Alcohol. World J. Pharm. Pharmaceut. Sci. 2014, 3, 993.

(2) Van Bogaert, I. N. A.; Saerens, K.; De Muynck, C.; Develter, D.; Soetaert, W.; Vandamme, E. J. Microbial Production and Application of Sophorolipids. Appl. Microbiol. Biotechnol. 2007, 76, 23-34.

(3) Silveira, V. A. I.; Freitas, C. A. U. Q.; Celligoi, M. A. P. C. Antimicrobial Applications of Sophorolipid from Candida Bombicola: A Promising Alternative to Conventional Drugs. J. Appl. Biol. Biotechnol. 2018, 6, 87-90.

(4) Joshi-Navare, K.; Shiras, A.; Prabhune, A. DifferentiationInducing Ability of Sophorolipids of Oleic and Linoleic Acids Using a Glioma Cell Line. Biotechnol. J. 2011, 6, 509-512.

(5) Borsanyiova, M.; Patil, A.; Mukherji, R.; Prabhune, A.; Bopegamage, S. Biological Activity of Sophorolipids and Their Possible Use as Antiviral Agents. Folia Microbiol. 2016, 61, 85-89.

(6) Nawale, L.; Dubey, P.; Chaudhari, B.; Sarkar, D.; Prabhune, A. Anti-Proliferative Effect of Novel Primary Cetyl Alcohol Derived Sophorolipids against Human Cervical Cancer Cells HeLa. PLoS One 2017, 12, No. e0174241.

(7) Van Bogaert, I.; Fleurackers, S.; Van Kerrebroeck, S.; Develter, D.; Soetaert, W. Production of New-to-Nature Sophorolipids by Cultivating the Yeast Candida Bombicola on Unconventional Hydrophobic Substrates. Biotechnol. Bioeng. 2011, 108, 734-741.

(8) Felse, P. A.; Shah, V.; Chan, J.; Rao, K. J.; Gross, R. A. Sophorolipid Biosynthesis by Candida Bombicola from Industrial Fatty Acid Residues. Enzyme Microb. Technol. 2007, 40, 316-323.

(9) Daverey, A.; Pakshirajan, K.; Sumalatha, S. Sophorolipids Production by Candida Bombicola Using Dairy Industry Wastewater. Clean Technol. Environ. Policy 2011, 13, 481-488.

(10) Zhang, J.; Saerens, K. M. J.; van Bogaert, I. N. A.; Soetaert, W. Vegetable Oil Enhances Sophorolipid Production by Rhodotorula Bogoriensis. Biotechnol. Lett. 2011, 33, 2417-2423.

(11) Morya, V. K.; Park, J.-h.; Kim, T. J.; Jeon, S.; Kim, E.-K. Production and Characterization of Low Molecular Weight Sophorolipid under Fed-Batch Culture. Bioresour. Technol. 2013, 143, 282-288.

(12) van Bogaert, I. N. A.; Roelants, S.; Develter, D.; Soetaert, W. Sophorolipid Production by Candida Bombicola on Oils with a Special Fatty Acid Composition and Their Consequences on Cell Viability. Biotechnol. Lett. 2010, 32, 1509-1514.

(13) Jezierska, S.; Claus, S.; Van Bogaert, I. Yeast Glycolipid Biosurfactants. FEBS Lett. 2018, 592, 1312-1329.

(14) Brakemeier, A.; Lang, S.; Wullbrandt, D.; Merschel, L.; Benninghoven, A.; Buschmann, N.; Wagner, F. Novel Sophorose Lipids from Microbial Conversion of 2-Alkanols. Biotechnol. Lett. 1995, 17, 1183-1188.

(15) Cavalero, D. A.; Cooper, D. G. The Effect of Medium Composition on the Structure and Physical State of Sophorolipids Produced by Candida Bombicola ATCC 22214. J. Biotechnol. 2003, $103,31-41$.
(16) Cuvier, A.-S.; Babonneau, F.; Berton, J.; Stevens, C. V.; Fadda, G. C.; Péhau-Arnaudet, G.; Le Griel, P.; Prévost, S.; Perez, J.; Baccile, N. Nanoscale Platelet Formation by Monounsaturated and Saturated Sophorolipids under Basic PH Conditions. Chem.-Eur. J. 2015, 21, 19265-19277.

(17) Baccile, N.; Babonneau, F.; Jestin, J.; Pehau-Arnaudet, G.; Van Bogaert, I. Unusual, PH-Induced, Self-Assembly of Sophorolipid Biosurfactants. ACS Nano 2012, 6, 4763-4776.

(18) Andersen, F. A. Final Report on the Safety Assessment of Trichloroethane. Int. J. Toxicol. 2008, 27, 107-138.

(19) Burdock, G. A.; Carabin, I. G. Safety Assessment of Myristic Acid as a Food Ingredient. Food Chem. Toxicol. 2007, 45, 517-529.

(20) Duronio, R. J.; Rudnick, D. A.; Johnson, R. L.; Johnson, D. R.; Gordon, J. I. Myristic Acid Auxotrophy Caused by Mutation of S. Cerevisiae Myristoyl-CoA:Protein N-Myristoyltransferase. J. Cell Biol. 1991, 113, 1313-1330.

(21) Lobel, P.; Dahms, N. M.; Breitmeyer, J.; Chirgwin, J. M.; Kornfeld, S. Cloning of the bovine $215-\mathrm{kDa}$ cation-independent mannose 6-phosphate receptor. Proc. Natl. Acad. Sci. 1987, 84, 2233.

(22) Nguyen, L. N.; Trofa, D.; Nosanchuk, J. D. Fatty Acid Synthase Impacts the Pathobiology of Candida Parapsilosis in Vitro and during Mammalian Infection. PLoS One 2009, 4, No. e8421.

(23) Rama Mohan, T.; Alice Branton, T.; Gopal Nayak, D. T. Physical, Spectroscopic and Thermal Characterization of Biofield Treated Myristic Acid. J. Fundam. Renewable Energy Appl. 2015, 05, 1000180 .

(24) Shaw, D.; Corocoran, T. Surface Activity and Micelle Formation. Green Chem. 2002, 4.

(25) Jiménez-Peñalver, P.; Castillejos, M.; Koh, A.; Gross, R.; Sánchez, A.; Font, X.; Gea, T. Production and Characterization of Sophorolipids from Stearic Acid by Solid-State Fermentation, a Cleaner Alternative to Chemical Surfactants. J. Clean. Prod. 2018, 172, 2735-2747.

(26) Ashby, R. D.; Solaiman, D. K. Y.; Foglia, T. A. Property Control of Sophorolipids: Influence of Fatty Acid Substrate and Blending. Biotechnol. Lett. 2008, 30, 1093-1100.

(27) Díaz De Rienzo, M. A.; Stevenson, P.; Marchant, R.; Banat, I. M. Antibacterial Properties of Biosurfactants against Selected GramPositive and -Negative Bacteria. FEMS Microbiol. Lett. 2016, 363, fnv224.

(28) Kim, K.; Yoo, D.; Kim, Y.; Lee, B.; Shin, D.; Kim, E. K. Characteristics of Sophorolipid as an Antimicrobial Agent. J. Microbiol. Biotechnol. 2002, 12, 235-241.

(29) Joshi-Navare, K.; Prabhune, A. A Biosurfactant-Sophorolipid Acts in Synergy with Antibiotics to Enhance Their Efficiency. Biomed Res. Int. 2013, 2013, 1.

(30) McGaw, L. J.; Jäger, A. K.; Van Staden, J. Antibacterial Effects of Fatty Acids and Related Compounds from Plants. South Afr. J. Bot. 2002, 68, 417-423.

(31) Dengle-Pulate, V.; Dubey, P.; Bhagwat, S.; Prabhune, A. HPLCMS, HRMS Analysis Of Microbial Acid Free, Shortchain Alkyl Sophorosides. World J. Pharm. Pharmaceut. Sci. 2015, 4, 2562.

(32) Shah, S.; Prabhune, A. Purification by Silica Gel Chromatography Using Dialysis Tubing and Characterization of Sophorolipids Produced from Candida Bombicola Grown on Glucose and Arachidonic Acid. Biotechnol. Lett. 2007, 29, 267-272. 